\title{
A Review on the Current Methods of Railway Induced Vibration Attenuations
}

\author{
Amir Kamyab Moghaddam \\ Truss Engineering Group \\ Ontario, Canada
}

\begin{abstract}
Railway ground borne vibration is a major problem for high-speed and intercity trains. This problem causes many environmental as well as financial problems for railway companies. In the past decades, there have been numerous methods and strategies to avoid the excessive vibration from vehicles. Many of these methods have been tested and used in tracks and surrounding structures while others are still theories. This paper intends to discuss the current practice in railway vibration reduction and the effectiveness of each method for the different track, vehicle and structures. The methods are divided into three groups; in track, in the path and at the destination solutions. For each category, the results from state-of-the-art research and practice have been presented and conclusion on the appropriate methods and strategies for each case has been made.
\end{abstract}

Track, Vibration, attenuation, dynamics, frequency

Keywords: Track, Vibration, attenuation, dynamics, frequency

\section{INTRODUCTION}

Energy dissipation is necessary in almost all structures subjected to dynamic loading including dams and water structures [1], [2], Bridges [3], [4] and tunnels [5], [6]. Since dynamic loading applied on railway track is considerable, a detailed vibration analysis to dissipate energy produced by vehicles should be performed. This problem is especially important in case of high-speed trains.

Since the introduction of high-speed trains in 1964 in Japan, the track-induced vibration has become a major concern in high-speed and urban railways. This is an important environmental and structural issue that is responsible of defects in railway track as well as complains from those who live in track nearby [7].

This issue affects all types of tracks including conventional ballasted track [8],[9], ballastless tracks[10], [11], asphalted track [12] and even more modern rail transportation mode, maglevs [13]. The vibration analysis methods can be divided into three categories: (a) experimental methods; (b) analytical; and (c) numerical methods. There are also hybrid solutions which combine the advantages of each approach to derive better answers.

Analytical solutions have shown a great potential to solve the problem and perform parametric studies to evaluate the impact of many influential parameters on vibration level of vehicle, track and structures. However, application of this approach usually causes the problem to be very complicated which reduces its effectiveness especially in case of threedimensional modeling and the authors have to oversimplify the model or make it very complicated [14], [15]. It is also shown that simplified linear models that most researchers adapted in their work is not capable of producing accurate solutions[16], [17]. Numerical simulations make the procedures easier but still most numerical models are computationally expensive with many degrees of freedom and huge amount of time is required to solve the equations [18]. Consequently, some authors try to combine different numerical methods [19], [20] or use the experimental and laboratory results [21], [22].
The goal of this paper is to probe into different methods of rail vibrations and compare the results from different methods to give an understanding of merits of each method in different conditions of train operations. It is also the aim of this study to classify the methods based on the location of vibration reduction measures; namely, in track, in the path and at the destination (or structures).

\section{TRACK BASED SOLUTIONS}

The most common way to reduce vibration is to find measures in railroad track or the source of excitations. Since the vibration has not been propagated yet, it can be effectively attenuated by methods that follow.

Rail fastening system has been used to connect rail to sleepers. There are two kind of fastening system: rigid and flexible fasteners. Flexible fastening system provide better vibration attenuation in track [23]. It is also shown that different flexible fastening systems are capable of bearing repetitive loading from vehicles and their fatigue life is satisfactory for different train speed and axle load [24].

Eitzenberger in his literature review on train induced vibrations in tunnels showed that flexible fastening system attenuate vibrations with a frequency between 30 to $50 \mathrm{~Hz}$ and maximum vibration reduction of $10 \mathrm{~dB}$ can be achieved [25].

Figure. 1 shows the vibration reduction due to using flexible fastening systems. As it can be seen in the figure with increasing the frequency, vibration decreases and there is a total difference of $18 \mathrm{~dB}$ between flexible and non-flexible fastening systems [26]. Rail pad stiffness also significantly affect the track stiffness and its vibration modes. It is also shown that the condition of rail pads affects the resonance frequency of sleepers which change the track frequencies and reduces the risk of resonance [27].

Other solution to decrease vibration in railway track is elastic layers that are capable of absorbing energy. There are a couple of elastic pads developed for track namely; rail pads, under sleeper pads, and under slab pads. 


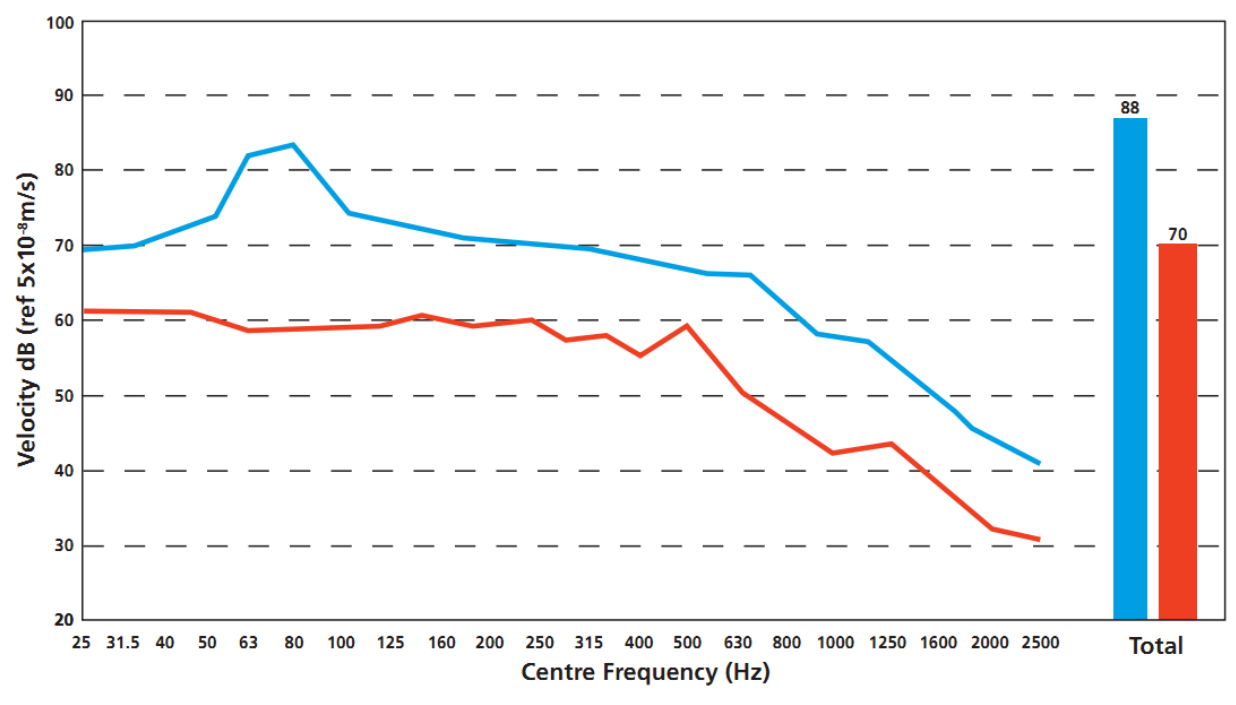

Figure. 1 Vibration velocity level before and after using flexible fasteners [26]

Elastic rail pads are common tools of vibration reduction. Thickness and elasticity of pads can be different for different track conditions. For example, Sol-Sánchez et al [28] considered the use of deconstructed tire rail pads in railroad tracks and concluded that for a high-speed rail track, rail pad thickness should be greater than $7.5 \mathrm{~mm}$, while for conventional tracks, $7.5 \mathrm{~mm}$ or less pads would be enough to attenuate vibration.

Under sleeper pads is another successful method of vibration reduction in railway track. Johansson et al [29] investigated the effect of pads on dynamic train-track interactions and their results showed that under sleeper pads reduces vibration of rail and sleepers and they are usually effective at frequencies below $250 \mathrm{~Hz}$.

This approach has been extended to slab tracks by using under slab pads and floating slab tracks. There are numerous analyses on the effect of pads on the track vibrations. The idea is to use elastic pads under sleeper and slab to change the vibration characteristics of the whole track. This is usually crucial in case of slab track because slab track has grater stiffness compared to conventional ballasted tracks and they are usually used in urban and high-speed lines. As a result, a thorough vibration analysis is needed for slab tracks.

To investigate the influence of pads with different stiffness and locations in slab track, Hui and $\mathrm{Ng}$ [30] conducted an analysis slab track on viaduct. Figure. 2 shows the under sleeper and side pads used in the analysis. The vibration isolation help reduce vibration in case of floating slabs with higher bending resonance frequencies but it is not suitable for high-speed tracks due to excessive deflections. It is reported that 10-45 vibration reduction can be achieved in the frequency range of $25-250 \mathrm{~Hz}$ bands.

Kuo et al [31] conducted a train-track dynamic interaction analysis to investigate a number of track parameters on track vibration including: rail clips, slab bearing and slab mass. Based on the results from the analyses, soft rail clips are very effective in decreasing wheel-rail contact forces and has little effect on track deflection. Slab pads are reported to be different and shows significant deflections so there should be a trade-off between environmental vibrations (propagated to the media) and train vibration (which affects ride comfort).
Increasing mass of slab is another solution to vibration problem. This solution is usually achieved by increasing the slab thickness, consequently, natural frequency of the whole structure reduces. A trade-off between costs of increasing thickness and vibration reduction is needed. The effectiveness of this methods depends totally on the excitation frequency and track type. For example, the findings from analyses indicate that rail vibration for the heavier tracks are slightly higher in case of high-speed tracks. So Arbitrary designs of slab tracks may cause amplification of dynamic responses in rail and slabs for different train speeds.

Since in Ballasted tracks, granular material are used, there are more vibration damping capacities compared to slab tracks. However, vibration propagation from high-speed tracks still exceeds the allowable vibration range introduced by track standards [32]. An elastic layer under ballast material as ballast mat layer is a solution to vibration problem in railway tracks [33].

A numerical finite element analysis performed by Costa et al [34] revealed that depending on the range of excitation frequency, ballast mat can be effective in vibration attenuation. For example, foe frequencies above $40 \mathrm{~Hz}$, up to $20 \mathrm{~dB}$ reduction in vibration has been observed. For lower frequency, it has been shown that isolated solution provide better results.

It is concluded that the introduction of mats leads to higher displacements of the rail than the non-isolated methods. It is suggested that to minimize this problem, the mat should be used under subbalast layer.

Subsoil condition proved to be very important factor in vibration reduction or amplification. Fesharaki and Hamedi [35] conducted a finite element analysis to delve into the effect of high-speed rail substructure on ground-borne vibrations. The research examined some parameters including train speed, train axle load and subsoil materials. The results of the study showed that track vibration highly depends on the material properties of track substructure and selecting proper material for track substructure could decrease the vibration by $30 \%$. Other researchers have taken into account the material type [12] and track stiffness [36]. All the study reach to the conclusion that changing the trackbed stiffness and damping has a great impact on track vibration. Some studies show that 


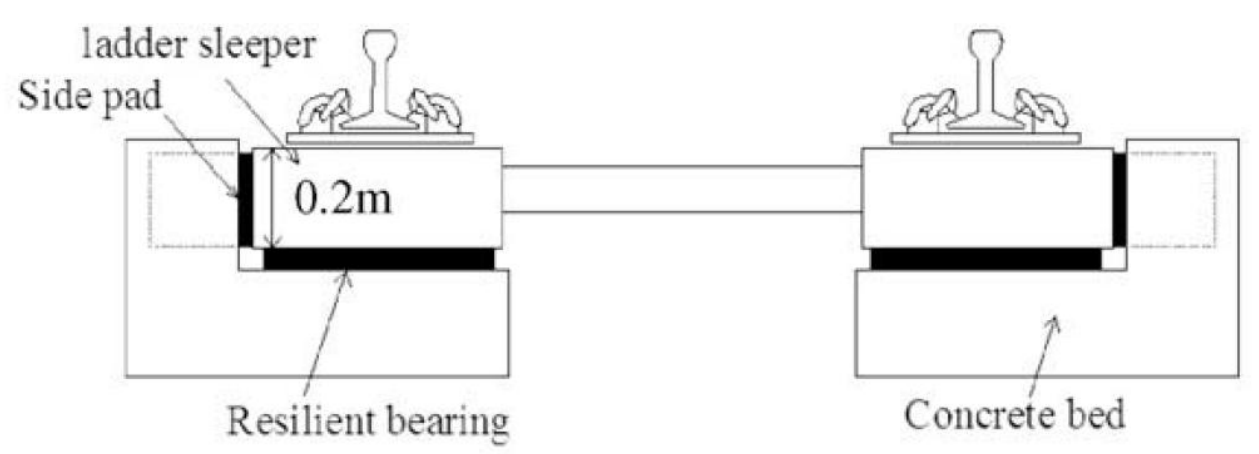

Figure. 2 under sleeper and side pads in slab track [30]

track materials such as embankments can be used to control vibrations. The height and stiffness and embankment is very important to dissipate vibration from high-speed tracks. [37]

A large number of studies have been done on the importance of track quality on track vibration [38], [39]. The finding indicate that track defects can increase vibration level more than $50 \%$ so controlling track deficiencies and regular track maintenance are a solution to track vibration.

\section{VIBRATION SOLUTIONS ON THE PROPAGATION PATH}

Another potential solution to railway vibration issue is to attenuate the energy of propagated wave in the surrounding media. In order to do so, the soil characteristics need to be changed. One possible method is open or filled trenches. Solid barriers can be filled by concrete or lime [40]. Figure. 3 shows trenches excavated with width "w" and height " $h$ " in the vibration propagation path to attenuate the energy of waves from railroad track.

Thompson et al [41] conducted a study by coupled finite element/boundary element methods to explore the impact of trench isolation for railway-induced vibration. It is found that the performance of trench in vibration reduction is influenced by the depth and stiffness of the soil layers. The overall vibration reduction achieved in this study is $10 \mathrm{~dB}$ which is for a $3 \mathrm{~m}$ deep trench in a soil with a $3 \mathrm{~m}$ deep surface layer.

The influence of trench width and slope was investigated and the results show that increasing the width of the open trench has little influence on vibration attenuation and the performance of trenches with side slopes ( 45 or 60 degrees) is very similar to that of a vertical trench. The important parameter that shows the performance of the trench is the stiffness per unit area of the barrier material.

Another investigation targeted on both open and in-filled trench with GeoFoam material performed by Alzawi and ElNaggar [42]. The results from the experimental study revealed that the GeoFoam barrier can be considered as an effective alternative for vibration reduction. The barrier can reduce vibrations up to $68 \%$. As part of this study, the depth of barrier explored. It is found that they are more effective for depth greater than 0.6 meters. The findings indicate that an important factor of trench effectiveness on vibration attenuation is the ratio of distance to track to depth of trench. For example, for deeper trench, they should be located at a farther distance from track.

Other researchers have done the same investigation by using numerical methods [43]. Ekanayake et al employed finite element code ABAQUS analyzed a three dimensional model of track and surrounding soil.

The results verifies the conclusion from previous study that width of barrier has little influence of its performance and the depth of barrier has a considerable impact on its vibration reduction ability. The material that might be used as the trench fill also investigated. For instance, comparing the performance of water filled and geofoam filled trenches shows that geofoam barriers outperforms water filled barriers. However, as the distance from the vibration source increases, both types of trenches perform similarly.

As it is mentioned in all vibration study, the frequency of vibration source and vibration characteristics of track and soil is the major item on the efficiency of the methods for vibration reduction. In this case, at lower frequencies, the effectiveness of both water filled and geofoam filled trenches are very close but for higher frequencies of excitation source, geofoam produces better attenuation.

\section{VIBRATION SOLUTIONS AT THE DESTINATION}

Most vibration attenuation methods are implemented at the source or along wave transmission path to the structures. It is believed that these methods are less expensive and more efficient than those performed at the already built structures. But in some cases, it is preferred to conduct vibration reduction measures at destination. For example, in case of a monumental or vibration sensitive building or structures, vibration reduction strategies at the building might be necessary.

Base isolation has been used for many years to reduce vibration in buildings. In 1930s some bearings have been used to reduce the "audible hum" in New York [44].

Evans and Himmel [45] published the results of measurements conducted to determine amplitude of vibration at various locations. The object of the project was to reduce vibration from a turbine and generator rotational frequencies. The analyses show the drilled piers' partial direct bearing on limestone causes vibration coupling. Reducing the bearing area of pier to limestone does not significantly affects the vibration.

Talbot [46] performed a detailed 3D dynamic model of piled foundation to explore the behavior of foundation vertical, horizontal and rotational directions. A generic model of baseisolation also generated by combining pile and building 


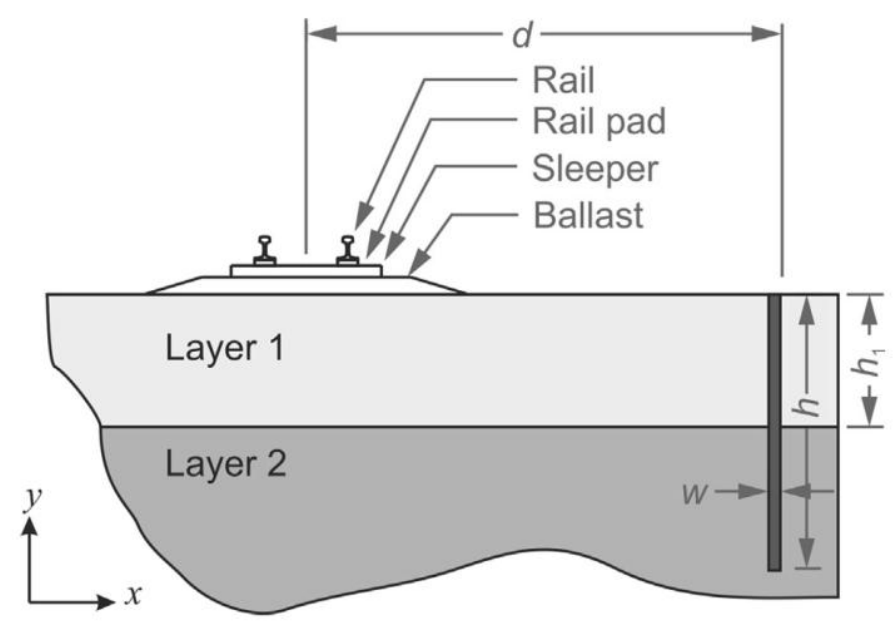

Figure. 3 soil barrier to reduce vibrations[41]

maximum vibration reduction of $15 \mathrm{~dB}$ can be achieved. Although effective on local resonance, Damping is found to be insignificant in vibration level.

\section{CONCLUSION}

Vibration of railway track is a very important issue in rail operation and design. With increasing trains' speed and loads the vibration problem has been arisen in many rail lines. Failure to address this issue properly causes great consequences form reducing life cycle of track structure to annoyance to people who live in track neighborhood. To solve this problem, several approaches have been used. From the location of measures points of view, three methods of vibration reduction can be used. Vibration attenuation at the source or railway track is the most popular method and proved to be more efficient compared to other methods. It usually includes using elastic layers under different parts of track including rail, sleeper, ballast and slab (in case of ballast-less track). The effectiveness of these solutions depends on the frequency of excitations and natural frequency of track. Successful methods can change the track frequencies considerably. The second approach is attenuation of vibration along the propagation path by using trenches. Different materials have been used to fill the trenches. The results of analyses for each material are different depending of the track structure, depth of trench and its distance from the vibration source. The third method or vibration reduction in the destination is least popular method and is usually very expensive. It is normally used to reduce vibration of a few monumental or sensitive buildings. As it is explained for other measures, the effectiveness of this method totally depends on the vibration from trains, track structure and natural frequency of the structure. The base isolation should be able to change the frequency of local structure, as a result, the resonance can be avoided. As a general conclusion, it is recommended that a detailed dynamic and vibration analysis should be performed for each case of track and building. So a perfect method of reducing vibration for a case may exacerbate the problem for another track with different natural frequency and track axle load and speed.

\section{REFERENCES}

[1] A. Hamedi, A. Mansoori, A. Shamsai, and S. Amirahmadian, "The Effect of End Sill and Stepped Slope on
Stepped Spillway Energy Dissipation,” J. Water Sci. Res., vol. 6, no. 1-15, 2014.

[2] A. Hamedi, A. Mansoori, I. Malekmohamadi, and H. Roshanaei, "Estimating Energy Dissipation in Stepped Spillways with Reverse Inclined Steps and End Sill," in World Environmental and Water Resources Congress, 2011, pp. 2528-2537.

[3] W. Zhang, J. Li, H. Hao, and H. Ma, "Damage detection in bridge structures under moving loads with phase trajectory change of multi-type vibration measurements," Mech. Syst. Signal Process., vol. 87, no. November 2016, pp. 410-425, 2017.

[4] A. Androus, H. M. Afefy, and K. Sennah, "Investigation of free vibration and ultimate behavior of composite twin-box girder bridges," J. Constr. Steel Res., vol. 130, pp. 177-192, 2017.

[5] Z. Yuan, A. Bostrom, and Y. Cai, "Benchmark solution for vibrations from a moving point source in a tunnel embedded in a half-space," J. Sound Vib., vol. 387, pp. 177193, 2017.

[6] J.-H. Lee, S.-K. Ahn, K.-C. Lee, C.-S. Bang, J.-H. Cho, and M. Sagong, "Wire saw cutting model development and performance investigation for vibration reduced tunnel excavation," Tunn. Undergr. Sp. Technol., vol. 63, pp. 144153, 2017.

[7] S. A. L. Suhairy, "Prediction of ground vibration from railways," Swedish National Testing and Research Institute, 2000.

[8] M. A. Sayeed and M. A. Shahin, "Three-dimensional numerical modelling of ballasted railway track foundations for high-speed trains with special reference to critical speed," Transp. Geotech., vol. 6, pp. 55-65, 2016.

[9] Z. Zhang, X. Zhang, H. Qiu, and M. Daddow, "Dynamic characteristics of track-ballast-silty clay with irregular vibration levels generated by high-speed train based on DEM," Constr. Build. Mater., vol. 125, pp. 564-573, 2016.

[10] W. Zhai, K. Wei, X. Song, and M. Shao, "Experimental investigation into ground vibrations induced by very high speed trains on a non-ballasted track," Soil Dyn. Earthq. Eng., vol. 72, pp. 24-36, 2015. 
[11] Z. P. Zeng, F. S. Liu, P. Lou, Y. G. Zhao, and L. M. Peng, "Formulation of three-dimensional equations of motion for train-slab track-bridge interaction system and its application to random vibration analysis," Appl. Math. Model., vol. 40, no. 11-12, pp. 5891-5929, 2013.

[12] G. D'Angelo, N. Thom, and D. Lo Presti, "Bitumen stabilized ballast: A potential solution for railway track-bed," Constr. Build. Mater., vol. 124, pp. 118-126, 2016.

[13] D. Zhou, J. Li, and K. Zhang, "Amplitude control of the track-induced self-excited vibration for a maglev system," ISA Trans., vol. 53, no. 5, pp. 1463-1469, 2014.

[14] X. Sheng, C. J. C. Jones, and D. J. Thompson, “A theoretical model for ground vibration from trains generated by vertical track irregularities," J. Sound Vib., vol. 272, no. 35, pp. 937-965, 2004.

[15] T. Mazilu, M. Dumitriu, C. Tudorache, and M. Sebeşan, "Using the Green's functions method to study wheelset/ballasted track vertical interaction," Math. Comput. Model., vol. 54, no. 1-2, pp. 261-279, 2011.

[16] T. Ishikawa, S. Miura, and E. Sekine, "Simple plastic deformation analysis of ballasted track under repeated moving-wheel loads by cumulative damage model," Transp. Geotech., vol. 1, no. 4, pp. 157-170, 2014.

[17] J. Sadeghi and M. Fesharaki, "Importance of Nonlinearity of Track Support System in Modeling of Railway Track Dynamics," Int. J. Struct. Stab. Dyn., vol. 13, no. 1, p. 16, 2013.

[18] M. Fesharaki and T.-L. Wang, "The Effect of Rail Defects on Track Impact Factors," Civ. Eng. J., vol. 2, no. 9, pp. 458-473, 2016.

[19] A. Aikawa, "Dynamic characterisation of a ballast layer subject to traffic impact loads using three-dimensional sensing stones and a special sensing sleeper," Constr. Build. Mater., vol. 92, pp. 23-30, 2014.

[20] D. C. Rizos and Z. Wang, "Coupled BEM-FEM solutions for direct time domain soil-structure interaction analysis," Eng. Anal. Bound. Elem., vol. 26, no. 10, pp. 877888, 2002.

[21] S. K. K. Hussaini, B. Indraratna, and J. S. Vinod, "A laboratory investigation to assess the functioning of railway ballast with and without geogrids," Transp. Geotech., vol. 6, pp. 45-54, 2016.

[22] N. C. dos Santos, A. Colaco, P. A. Costa, and R. Calcada, "Experimental analysis of track-ground vibrations on a stretch of the Portuguese railway network," Soil Dyn. Earthq. Eng., vol. 90, pp. 358-380, 2016.

[23] C. Esveld, Modern Railway Track, 2nd ed. MRT Publications, 2001.

[24] J. Sadeghi, M. Fesharaki, and A. Khajehdezfuly, "Influences of train speed and axle loads on life cycle of rail fastening clips," Trans. Can. Soc. Mech. Eng., vol. 39, no. 1, pp. 1-11, 2015.

[25] A. Eitzenberger, "Train-induced Vibrations in Tunnels - A Review,” Dep. Civil, Min. Environ. Eng., p. 100, 2008.

[26] M. Rantatalo and T. Xin, "Review of countermeasures and regulations for railway induced ground vibrations in tunnels," pp. 1-23, 2013.
[27] S. Kaewunruen and A. M. Remennikov, "Sensitivity analysis of free vibration characteristics of an in situ railway concrete sleeper to variations of rail pad parameters," J. Sound Vib., vol. 298, no. 1-2, pp. 453-461, 2006.

[28] M. Sol-Sánchez, F. Moreno-Navarro, and M. C. RubioGámez, "The use of deconstructed tire rail pads in railroad tracks: Impact of pad thickness," Mater. Des., vol. 58, pp. 198-203, 2014.

[29] A. Johansson, J. C. O. Nielsen, R. Bolmsvik, A. Karlström, and R. Lundén, "Under sleeper pads-Influence on dynamic train-track interaction," Wear, vol. 265, no. 9-10, pp. 1479-1487, 2008.

[30] C. K. Hui and C. F. Ng, "The effects of floating slab bending resonances on the vibration isolation of rail viaduct," Appl. Acoust., vol. 70, no. 6, pp. 830-844, 2009.

[31] C. M. Kuo, C. H. Huang, and Y. Y. Chen, "Vibration characteristics of floating slab track," J. Sound Vib., vol. 317, no. 3-5, pp. 1017-1034, 2008.

[32] Carl E. Hanson; David A. Towers; and Lance D. Meister, "Transit Noise and Vibration Impact Assessment FTA Federal Transit Administration,” no. May, pp. 1-261, 2006.

[33] C. E. Hanson and H. L. Singleton, "Performance of ballast mats on passenger railroads: Measurement vs. projections," J. Sound Vib., vol. 293, no. 3-5, pp. 873-877, 2006.

[34] P. Alves Costa, R. Calçada, and A. Silva Cardoso, "Ballast mats for the reduction of railway traffic vibrations. Numerical study," Soil Dyn. Earthq. Eng., vol. 42, pp. $137-$ 150, 2012.

[35] M. Fesharaki and A. Hamedi, "Effects of High-Speed Rail substructure on ground-borne vibrations," Florida Civ. Eng. J., vol. 2, pp. 38-47, 2016.

[36] X. Sheng, T. Zhong, and Y. Li, "Vibration and sound radiation of slab high-speed railway tracks subject to a moving harmonic load," vol. 395, pp. 160-186, 2017.

[37] M. Esmaeili, J. Sadeghi, and M. Fesharaki, "Vehicle dynamic interaction with railway track embankment," Proc. Inst. Civ. Eng. - Transp., vol. 167, no. 1, pp. 15-26, 2014.

[38] M. Fesharaki, "An Investigation on the Effect of Rail Corrugation on Track Response," Int. J. Sci. Eng. Appl., vol. 5, no. 7, pp. 408-412, 2016.

[39] T. X. Wu, "Effects on short pitch rail corrugation growth of a rail vibration absorber/damper," Wear, vol. 271, no. 1-2, pp. 339-348, 2011.

[40] California High-Speed Rail Authority, "Appendix: Noise and Vibration Mitigation Guidelines," 2011.

[41] D. J. Thompson, J. Jiang, M. G. R. Toward, M. F. M. Hussein, E. Ntotsios, A. Dijckmans, P. Coulier, G. Lombaert, and G. Degrande, "Reducing railway-induced ground-borne vibration by using open trenches and soft- fi lled barriers," Soil Dyn. Earthq. Eng., vol. 88, pp. 45-59, 2016.

[42] A. Alzawi and M. Hesham El Naggar, "Full scale experimental study on vibration scattering using open and infilled (GeoFoam) wave barriers," Soil Dyn. Earthq. Eng., vol. 31, no. 3, pp. 306-317, 2011. 
International Journal of Science and Engineering Applications

Volume 6 Issue 04, 2017, ISSN-2319-7560 (Online)

[43] S. D. Ekanayake, D. S. Liyanapathirana, and C. J. Leo, "Attenuation of ground vibrations using in-filled wave barriers," Soil Dyn. Earthq. Eng., vol. 67, pp. 290-300, 2014.

[44] R.A. Waller, Building on springs. Pergamon Press, 1969.

[45] J. B. Evans and C. Himmel, "Vibration mitigation design for an academic building adjacent to a turbinegenerator power plant," Acta Acust., vol. 89, no. SUPP., pp. $1-6,2003$

[46] J. P. Talbot, "On the Performance of Base-Isolated Buildings : A Generic Model," University of Cambridge, PhD dissertation, 2001. 